\title{
Article \\ Optimization of Oxygen Evolution Reaction with Electroless Deposited Ni-P Catalytic Nanocoating
}

\author{
Sergio Battiato ${ }^{1, *(\mathbb{D}}$, Mario Urso ${ }^{1}$, Salvatore Cosentino ${ }^{1}$, Anna Lucia Pellegrino ${ }^{2} \mathbb{D}$, Salvo Mirabella ${ }^{1}$ \\ and Antonio Terrasi ${ }^{1}$ \\ 1 IMM-CNR, Università di Catania, Via S. Sofia 64, I-95123 Catania, Italy; mario.urso@ct.infn.it (M.U.); \\ salvatore.cosentino@ct.infn.it (S.C.); salvo.mirabella@dfa.unict.it (S.M.); antonio.terrasi@ct.infn.it (A.T.) \\ 2 Dipartimento di Scienze Chimiche, Università degli Studi di Catania, INSTM UdR Catania, Viale Andrea \\ Doria 6, I-95125 Catania, Italy; annalucia.pellegrino@unict.it \\ * Correspondence: sergio.battiato@dfa.unict.it
}

check for updates

Citation: Battiato, S.; Urso, M.; Cosentino, S.; Pellegrino, A.L.; Mirabella, S.; Terrasi, A. Optimization of Oxygen Evolution Reaction with Electroless Deposited Ni-P Catalytic Nanocoating. Nanomaterials 2021, 11, 3010. https://doi.org/10.3390/ nano11113010

Academic Editor:

Palaniappan Subramanian

Received: 7 October 2021

Accepted: 5 November 2021

Published: 9 November 2021

Publisher's Note: MDPI stays neutral with regard to jurisdictional claims in published maps and institutional affiliations.

Copyright: (C) 2021 by the authors. Licensee MDPI, Basel, Switzerland. This article is an open access article distributed under the terms and conditions of the Creative Commons Attribution (CC BY) license (https:// creativecommons.org/licenses/by/ $4.0 /)$.

\begin{abstract}
The low efficiency of water electrolysis mostly arises from the thermodynamic uphill oxygen evolution reaction. The efficiency can be greatly improved by rationally designing lowcost and efficient oxygen evolution anode materials. Herein, we report the synthesis of Ni-P alloys adopting a facile electroless plating method under mild conditions on nickel substrates. The relationship between the Ni-P properties and catalytic activity allowed us to define the best conditions for the electroless synthesis of highperformance Ni-P catalysts. Indeed, the electrochemical investigations indicated an increased catalytic response by reducing the thickness and $\mathrm{Ni} / \mathrm{P}$ ratio in the alloy. Furthermore, the Ni-P catalysts with optimized size and composition deposited on Ni foam exposed more active sites for the oxygen evolution reaction, yielding a current density of $10 \mathrm{~mA}$ $\mathrm{cm}^{-2}$ at an overpotential as low as $335 \mathrm{mV}$, exhibiting charge transfer resistances of only a few ohms and a remarkable turnover frequency (TOF) value of $0.62 \mathrm{~s}^{-1}$ at $350 \mathrm{mV}$. The present study provides an advancement in the control of the electroless synthetic approach for the design and large-scale application of high-performance metal phosphide catalysts for electrochemical water splitting.
\end{abstract}

Keywords: oxygen evolution reaction; nickel phosphide; electrocatalysis; electroless deposition; catalytic nanocoatings

\section{Introduction}

Electrochemical water splitting has aroused unremitting attention as a promising method to produce $\mathrm{H}_{2}$, a clean and sustainable energy carrier considered an alternative to fossil fuels [1-3]. Despite its great potential, electrolytic water generation is a thermodynamically uphill process, since the two semi-reactions involved, the hydrogen evolution reaction (HER) and the oxygen evolution reaction (OER), are constrained by sluggish kinetics, particularly the OER, which undergoes a complex four-electron transfer process [4,5]. At present, the main strategy to enhance the efficiency of the OER half-reaction involves the use of noble-metal-based (e.g., $\mathrm{RuO}_{2}$ and $\mathrm{IrO}_{2}$ ) electrocatalysts, on account of their superior catalytic performance [6]. Nonetheless, the large-scale application of these materials is hampered by their low abundance and high cost [7-9]. Consequently, it is mandatory to seek earth-abundant and efficient OER electrocatalysts [10]. In this context, transition metalbased catalysts are undoubtedly compelling candidates in view of their abundancy, cost effectiveness and great potential in the field of OER for electrolytic water splitting [11,12]. Among the multitude of transition metals which have been explored as OER electrocatalysts, Ni-based catalysts have been widely demonstrated to have noteworthy catalytic properties [13-16]. Several research studies have proved that alloying Ni with P provides a beneficial effect for the OER process [17-20]. The improved catalytic activity of transition metal phosphide catalysts arises from the partially charged nature of the $\mathrm{Ni}\left(\delta^{+}\right)$and $\mathrm{P}$ $\left(\delta^{-}\right)$atoms in the Ni-P alloy. In particular, $\mathrm{Ni} \delta^{+}$and $\mathrm{P} \delta^{-}$promote the formation of more 
catalytically active $\mathrm{NiOOH}$ and phosphate species at the near surface of the catalysts that act as the active phases during the OER, thus improving the catalytic activities [21,22].

A plethora of methods have been proposed to prepare nickel phosphide catalytic materials including straightforward hydrothermal [23], electrodeposition [24,25] and electroless deposition [26] techniques.

Although the above methods have been successful in the development of nickel phosphides with a discrete OER activity, the efficiency of these materials is not yet in step with that of the noble metals. In our opinion, a decisive enhancement of the catalytic efficiency of these catalysts may be obtained by a careful design of the electrocatalyst characteristics in terms of size, shape and composition. Favorably improving these properties can be achieved through proper control of the synthetic process employed for the realization of the Ni-P catalysts. In addition, the high catalyst loading of these materials that is often reported in the abovementioned synthetic methods affects the mass transport of reactants and ions due to the thicker catalyst layers. An effective strategy to enhance the inherent activities of electrocatalysts is the realization of ultra-small sized catalysts since the exposed active sites can offer large specific surface areas for improving the electron and mass transfer.

Triggered by these considerations, we dedicated ourselves to comprehensively investigating the electroless synthesis of Ni-P catalysts on nickel substrates, whose fine control led to the realization of few-nanometer-sized amorphous $\mathrm{Ni}-\mathrm{P}$ alloys with tunable $\mathrm{Ni} / \mathrm{P}$ ratios. An in-depth understanding encompassing the synthesis parameters-film properties and film property-OER performance relationships-was achieved. Electrochemical measurements showed that the highest OER performance was attained in the thinnest $\mathrm{Ni}-\mathrm{P}$ nanocoatings. Tuning the Ni-P composition plays a crucial role in governing the electrocatalytic activity of the alloy, as demonstrated by the increased performance of the $\mathrm{Ni}-\mathrm{P}$ alloys with the highest phosphorus content. Moreover, the samples deposited on nickel foam showed prominently enhanced OER activity, needing an overpotential of only $335 \mathrm{mV}$ to sustain a current density of $10 \mathrm{~mA} \mathrm{~cm}^{-2}$, showing low Tafel slope $\left(70 \mathrm{mV} \mathrm{dec}^{-1}\right)$ and charge transfer resistance ( $4 \mathrm{ohms}$ ) values. Noticeably, the activity of the present Ni-P alloy is amid the best performances of transition metal phosphides.

Furthermore, the present low-cost and controllable synthetic approach can be easily extended to fabricate other ultra-small metal phosphide materials with tailored metalphosphorus compositions, providing a significant platform for the future development of high-efficiency electrocatalysts.

\section{Materials and Methods}

\subsection{Substrates}

The substrates used for this study consisted of a $100 \mathrm{~nm}$ nickel layer deposited by evaporation on silicon substrates (hereafter Ni flat), and nickel foams (Goodfellow Inc., Huntingdon, England, thickness $1.6 \mathrm{~mm}$, porosity $\geq 95 \%$ ) purposely chosen to realize an electrode with high porosity. Prior to synthesis, both substrates were carefully cleaned with acetone, isopropanol and deionized (DI) water and dried in $\mathrm{N}_{2}$.

\subsection{Preparation of $\mathrm{Ni}-\mathrm{P}$ Catalysts}

The electroless Ni-P alloys were synthesized in a solution containing $25 \mathrm{~g} \mathrm{~L}^{-1}$ nickel sulfate hexahydrate, which serves as the nickel source, $20 \mathrm{~g} \mathrm{~L}^{-1}$ sodium citrate as a complexing agent and $30 \mathrm{~g} \mathrm{~L}^{-1}$ ammonium fluoride as a stabilizer. Sodium hypophosphite, which acts as a reducing agent, was added into the bath in different concentrations in order to optimize the compositions of the Ni-P alloys, while the concentrations of all other reagents were kept constant. The corresponding alloy coatings are hereafter referred to as Ni- $\mathrm{P}_{17}, \mathrm{Ni}-\mathrm{P}_{21}$ and Ni- $\mathrm{P}_{24}$ on the basis of the P percentage in the alloy (as calculated from Rutherford backscattering spectrometry) corresponding to the addition of 7.5, 15 and $30 \mathrm{~g} \mathrm{~L}^{-1}$ sodium hypophosphite in the bath (see Table 1). 
Table 1. Composition of various nanostructured Ni-P electrocatalysts realized by tuning the hypophosphite concentration.

\begin{tabular}{|c|c|c|c|}
\hline Component & $\mathbf{N i}-\mathbf{P}_{17}$ & $\mathrm{Ni}-\mathrm{P}_{21}$ & $\mathrm{Ni}-\mathrm{P}_{24}$ \\
\hline $\mathrm{NaH}_{2} \mathrm{PO}_{2} \cdot \mathrm{H}_{2} \mathrm{O}\left(\mathrm{g} \mathrm{L}^{-1}\right)$ & 7.5 & 15 & 30 \\
\hline
\end{tabular}

The $\mathrm{pH}$ of the solution was measured to be 5.05 , the plating bath was heated to $70{ }^{\circ} \mathrm{C}$ and the thickness of the coatings was controlled by varying the deposition time $(3,4$ and $6 \mathrm{~min})$.

\subsection{Characterization}

Film structure was analyzed by X-ray diffraction using a Smartlab Rigaku diffractometer (Rigaku Corporation, Tokyo, Japan) in grazing incidence mode $\left(0.5^{\circ}\right)$, equipped with a rotating anode of $\mathrm{Cu} \mathrm{K}_{\alpha}$ radiation operating at $45 \mathrm{kV}$ and $200 \mathrm{~mA}$. The surface morphology was characterized using a scanning electron microscope (Gemini field emission SEM Carl Zeiss SUPRA 25, Carl Zeiss AG, Oberkochen, Germany). Rutherford backscattering spectrometry (RBS) measurements were carried out using a $2.0 \mathrm{MeV} \mathrm{He}^{+}$ion beam that hits the sample surface at normal incidence, while backscattered $\mathrm{He}^{+}$atoms were detected at an angle of $15^{\circ}$ out of the normal to the surface. The Ni-P dose in the Ni-P alloys was determined by RBS spectra simulation using SIMNRA software [27]. Once the Ni-P dose is known, the layer thickness is derived by dividing the Ni-P dose in at $/ \mathrm{cm}^{2}$ for the atomic density, expressed in at $/ \mathrm{cm}^{3}$, which is calculated as follows:

$$
\text { Ni-P atomic density }\left(\frac{\mathrm{at}}{\mathrm{cm}^{3}}\right)=\frac{\mathrm{Ni}-\mathrm{P} \text { mass density }\left(\frac{\mathrm{g}}{\mathrm{cm}^{3}}\right)}{\mathrm{Ni}-\mathrm{P} \text { molecular weight }\left(\frac{\mathrm{g}}{\mathrm{mol}}\right)} \cdot \operatorname{Avogadro's~number}\left(\frac{\mathrm{at}}{\mathrm{mol}}\right)
$$

The Ni-P mass density depends on the Ni-P composition [28]; thus, the resulting atomic densities were $8.48 \cdot 10^{22} \mathrm{Ni}-\mathrm{P} / \mathrm{cm}^{3}, 8.65 \cdot 10^{22} \mathrm{Ni}-\mathrm{P} / \mathrm{cm}^{3}$ and $8.79 \cdot 10^{22} \mathrm{Ni}-\mathrm{P} / \mathrm{cm}^{3}$ for the $\mathrm{Ni}-\mathrm{P}_{17}, \mathrm{Ni}-\mathrm{P}_{21}$ and $\mathrm{Ni}-\mathrm{P}_{24}$ samples, respectively.

\subsection{Electrochemical Tests}

Catalytic performances of the Ni-P catalysts were evaluated using a Versastat-4 potentiostat in a three-electrode setup with a Pt wire as the cathode, a saturated calomel electrode (SCE) as the reference electrode and $\mathrm{Ni}-\mathrm{P}$ catalysts on $\mathrm{Ni}$ flat and $\mathrm{Ni}$ foam as the working electrodes. The current density was normalized to the geometrical surface area, and the measured potentials vs. $\mathrm{Hg} / \mathrm{Hg}_{2} \mathrm{Cl}_{2}$ were converted to the reversible hydrogen electrode (RHE) according to the equation [29,30]

$$
\mathrm{E}_{\mathrm{RHE}}=\mathrm{E}_{\mathrm{Hg}} / \mathrm{Hg}_{2 \mathrm{Cl} 2}+0.059 \mathrm{pH}+0.241
$$

All samples were activated acquiring ten cyclic voltammetry $(\mathrm{CV})$ cycles at $10 \mathrm{mV} \mathrm{s}^{-1}$ until the curves were stable [31,32], and all potentials measured were manually corrected by $\mathrm{iR}_{\mathrm{u}}$ compensation as follows:

$$
\eta=\eta^{\prime}-\mathrm{i} R_{\mathrm{u}}
$$

where $\mathrm{i}$ is the current collected at the electrode, while $R_{u}$ [ohm] is the intercept on the real axis of the Nyquist plots (real vs. imaginary part of the impedance, Z) obtained from the electrochemical impedance spectroscopy (EIS) measurements. Steady-state Tafel plots were acquired from chronopotentiometric (CP) measurements in steps from 0.1 to $10 \mathrm{~mA} \mathrm{~cm}^{-2}$, each held for $3 \mathrm{~min}$.

EIS was performed in potentiostatic mode from 100 to $0.1 \mathrm{kHz}$, with an AC voltage of $5 \mathrm{mV}$. All measurements were performed at room temperature and atmospheric pressure, in a one-compartment electrochemical Teflon cell filled with $1 \mathrm{M} \mathrm{KOH}$ as the supporting electrolyte. 


\section{Results and Discussion}

$\mathrm{Ni}-\mathrm{P}$ alloys with various percentages of $\mathrm{P}$ were synthesized using a facile electroless deposition approach.

The formation process is driven by an autocatalytic reduction reaction on the surface of the Ni substrate. Ni is reduced by capturing the electrons provided by the reducing agent $\left(\mathrm{NaH}_{2} \mathrm{PO}_{2}\right)$, while zero-valence $\mathrm{P}$ and $\mathrm{H}_{2}$ are formed as by-products.

The chemical reaction can be described as follows [33]:

$$
\begin{gathered}
\mathrm{Ni}^{2+}+\mathrm{H}_{2} \mathrm{PO}^{-}{ }_{2}+\mathrm{H}_{2} \mathrm{O} \rightarrow \mathrm{Ni}+\mathrm{HPO}_{3}{ }^{2-}+3 \mathrm{H}^{+} \\
3 \mathrm{H}_{2} \mathrm{PO}^{-}{ }_{2} \rightarrow \mathrm{H}_{2} \mathrm{PO}^{-}{ }_{3}+\mathrm{H}_{2} \mathrm{O}+2 \mathrm{OH}^{-}+2 \mathrm{P} \\
\mathrm{H}_{2} \mathrm{PO}^{-}{ }_{2}+\mathrm{H}_{2} \mathrm{O} \rightarrow \mathrm{H}_{2} \mathrm{PO}^{-}{ }_{3}+\mathrm{H}_{2}
\end{gathered}
$$

Scanning electron microscopic analysis was performed to understand the morphology and size of the product. Figure 1a shows the SEM image of the Ni substrate, presenting a homogeneous smooth surface. Figure $1 \mathrm{~b}$ shows the micrography of a $\mathrm{Ni}-\mathrm{P}_{24}$ film deposited on the same Ni substrate for $6 \mathrm{~min}$, which consists of a homogeneous layer with a grain size below $10 \mathrm{~nm}$. Interestingly, the higher-magnification image (inset figure) depicts the presence of pinholes scattered on the surface. These pinholes can be reasonably ascribed to the hydrogen evolution taking place during the plating process, as reported by other authors $[33,34]$. SEM analysis of a film after the OER is useful in evaluating how the surface of the catalyst is affected by the electrochemical activity; in this regard, the literature often reports major modifications of the morphology after the OER, indicating significant changes in the surface chemistry [35].

a

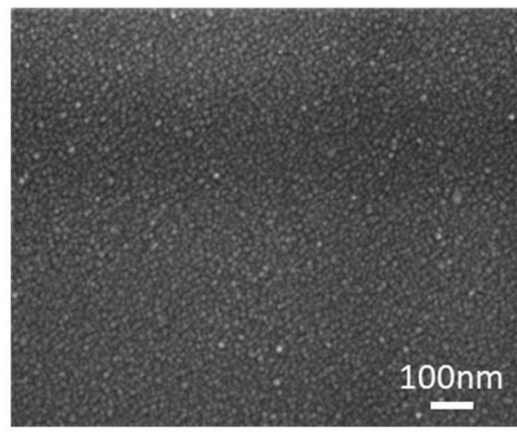

b

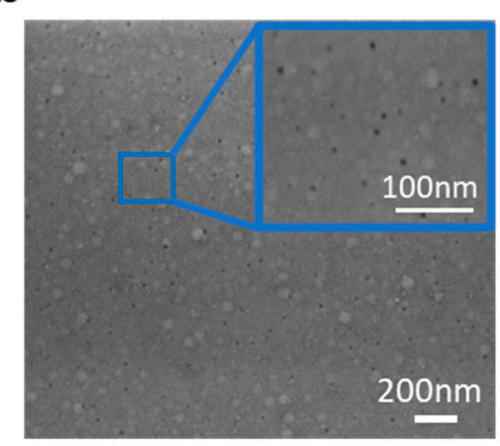

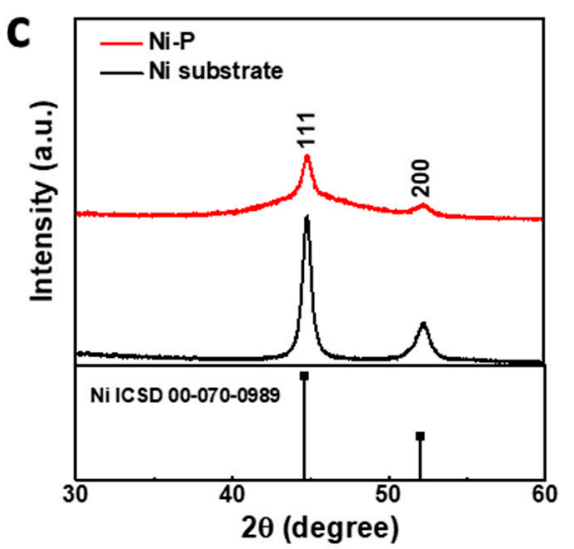

Figure 1. SEM images of (a) Ni substrate and (b) Ni-P 24 deposited for 6 min. (c) X-ray diffraction patterns of electrolessdeposited Ni-P (red pattern) and Ni substrate (black pattern).

In our case, the morphology of the same $\mathrm{Ni}-\mathrm{P}_{24}$ film after the oxygen evolution reaction (OER) was retained compared to the pristine one, as shown in Figure S1.

The phase purity of the synthesized materials was revealed using $X$-ray diffraction (XRD). The pattern of the nickel substrate was acquired as well and compared to that of the Ni-P films. It is worth noting that the grazing incidence acquisition mode allows us to detect only the extreme surface of the sample, thus avoiding the contribution of the underlying nickel substrate. In Figure 1c, the X-ray diffraction (XRD) pattern obtained for the nickel substrate (black pattern) shows characteristic peaks centered at $2 \theta=44.6^{\circ}$ and $52.1^{\circ}$ matching the reflections of the (111) and (200) lattice planes typical of the facecentered cubic (FCC) nickel phase (ICSD diffraction card 00-070-0989), which points to a crystalline nature of the substrate. Concerning the pattern obtained for the $\mathrm{Ni}-\mathrm{P}_{24}$ sample (red pattern), in this case, a diffuse scattering peak is clearly observable around $44.6^{\circ}$. The widening of this peak, commonly observed in electroless-deposited Ni-P alloys, is a 
hint that $\mathrm{P}$ has entered the face-centered cubic nickel lattice and clearly indicates that the as-deposited Ni-P is amorphous [17,36-38].

Figure 2 shows the RBS spectra of our Ni-P samples. In Figure 2a, we report the RBS spectra of the Ni-P coatings grown for $6 \mathrm{~min}$ at different hypophosphite concentrations. For all samples, we observed the presence of the following peaks: the peak at $1.17 \mathrm{MeV}$ is related to $\mathrm{He}^{+}$backscattered by $\mathrm{P}$, whereas the band diffused in the range between 1.32 and $1.52 \mathrm{MeV}$ arises from the $\mathrm{He}^{+}$backscattered by $\mathrm{Ni}$ of the substrate (lower energy) and $\mathrm{Ni}$ of the Ni-P film (higher energy). The height of each RBS signal depends on the atomic density and atomic number of the target. Moreover, an increase in the P signals with the increasing hypophosphite concentration was observed (the reader can compare the zoomed P regions of RBS spectra, shown in the inset of Figure 2a). The quantitative RBS analysis of the same spectra carried out by SIMNRA simulation allowed us to calculate the $\mathrm{Ni} / \mathrm{P}$ ratio in the alloys. The reason why the films' composition was determined at the longest deposition time of $6 \mathrm{~min}$ is that the calculation performed on the thickest samples is more reliable. Indeed, a physiological margin of error occurred in the simulation of the spectra of thinner samples (the sample deposited for $3 \mathrm{~min}$ had a thickness of only about $7 \mathrm{~nm}$ ), the substrate being constituted by the same Ni element. Concerning the synthesis characteristics, some research studies have described an incubation period before the beginning of Ni-P plating $[39,40]$. Here, we extrapolated the incubation time by fitting the curves of the Ni-P dose vs. the growth time, as reported in Figure 2b. Notably, the incubation time values found in the three samples are substantially superimposable, with a mean value of about $2.4 \mathrm{~min}$, indicating that the hypophosphite concentration does not impact this aspect of the synthesis.

a

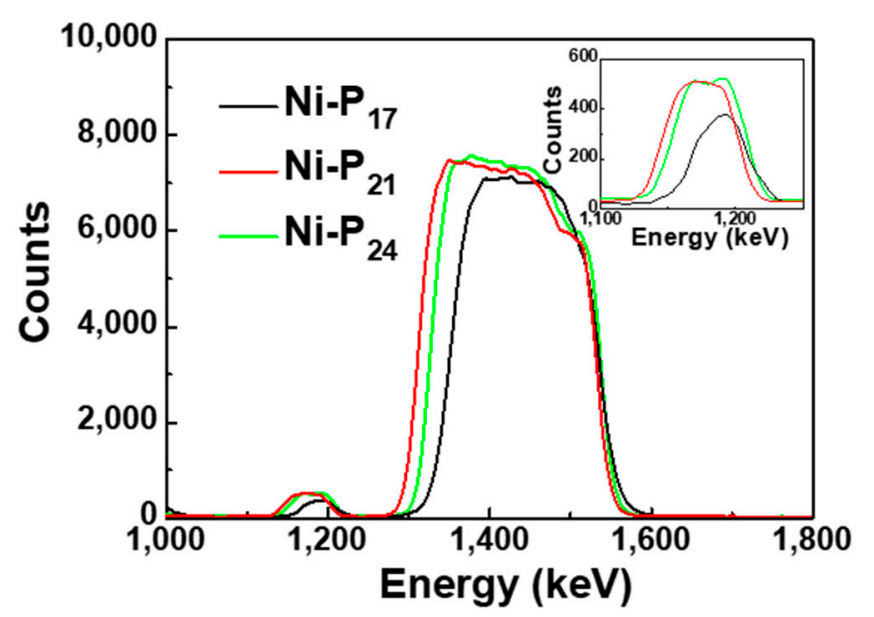

b

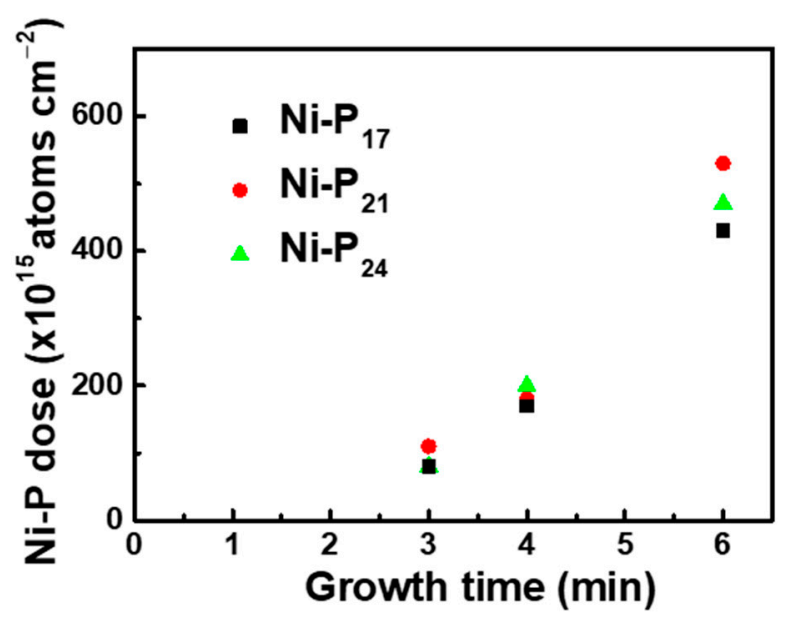

Figure 2. (a) Comparison of RBS spectra of Ni-P coatings with different phosphorus concentrations grown for 6 min. The inset reports a zoom in on the region of phosphorus. (b) Plot of the dose of Ni-P as a function of the growth time.

To reveal the OER activities of the as-prepared samples, various electrochemical measurements of Ni-P samples were carried out in alkaline media. In Figure 3a, we report a portion of the 10th $\mathrm{CV}$ cycle of $\mathrm{Ni}-\mathrm{P}_{24}$ samples deposited at different times in the region between 1.2 and $1.8 \mathrm{~V}$, where the typical charge transfer reactions occur. Firstly, a redox peak at $\sim 1.38 \mathrm{~V}$ (vs. RHE) is visible in the polarization plot, which can be safely attributed to the formation of surface $\mathrm{NiOOH}$ species, consistent with previous reports of other nickelbased electrocatalysts [41,42]. The comparison of the curves indicated that the Ni- $\mathrm{P}_{24}$ sample deposited for 3 min exhibited an improved OER performance, as evidenced by the overpotential of $388 \mathrm{mV}$ required to attain a current density of $10 \mathrm{~mA} \mathrm{~cm}^{-2}$, which is lower compared to the values obtained for $\mathrm{Ni}-\mathrm{P}_{21}$ deposited at longer times. In comparison, the bare nickel electrode showed poor electrochemical activity, evidencing the beneficial 
role of phosphorus in the catalytic activity. To further elucidate the electrode kinetics, electrochemical impedance spectroscopy (EIS) was performed. The experimental EIS spectra, shown in Figure 3b, were fitted by a simplified Randles circuit (inset of the same figure). Nyquist plots were acquired at a fixed potential of $1.6 \mathrm{~V}$ vs. RHE, since at this potential, all catalysts studied show appreciable OER activity, allowing a fair comparison of their charge transfer resistances [43]. Figure $3 \mathrm{~b}$ shows that the $\mathrm{Ni}-\mathrm{P}_{24}$ sample deposited for $3 \mathrm{~min}$ presented the lowest charge transfer resistance $\left(R_{\mathrm{ct}}\right)$, whose value was $40 \mathrm{ohms}$. The electrocatalytic kinetics involved in the OER of Ni-P alloys and the Ni substrate were further examined by corresponding Tafel plots, as reported in Figure 3c. The Tafel slope of Ni-P 24 deposited for 3 min was about $70 \mathrm{mV} \mathrm{dec}^{-1}$, which exceeds that of other Ni-P coatings and the nickel substrate, indicating that the oxygen evolution rate was more efficiently promoted for the thinnest Ni-P catalyst. According to an overall electrochemical property examination, the Ni-P catalysts showed a considerable dependence of their OER activity on the thickness, whose reduction positively influenced the performance. Similar results were found for samples with different phosphorous concentrations in the alloy (Figures S2 and S3 display the electrochemical analyses for samples Ni- $\mathrm{P}_{17}$ and $\mathrm{Ni}-\mathrm{P}_{21}$, respectively). As previously reported [32], the reduced activity metrics for the thicker samples can be attributed to a higher potential drop occurring from the substrate to the top of the sample, leaving a high portion of the film at a potential not sufficient to drive the electrochemical reaction.

a

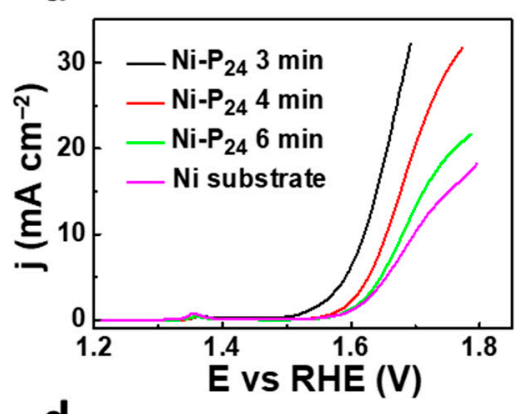

d

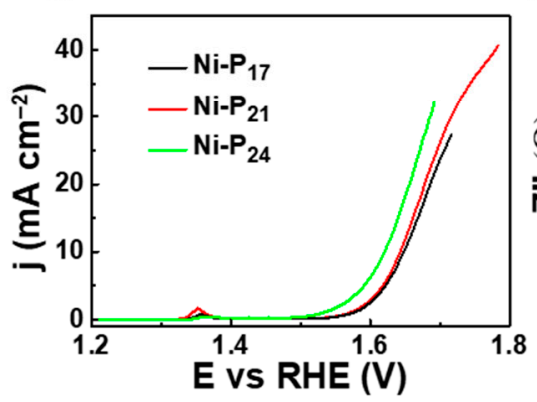

b

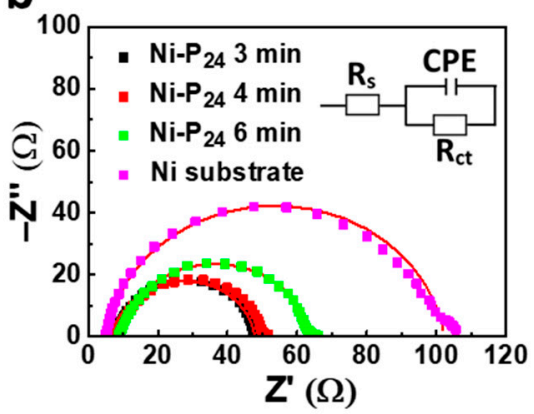

e

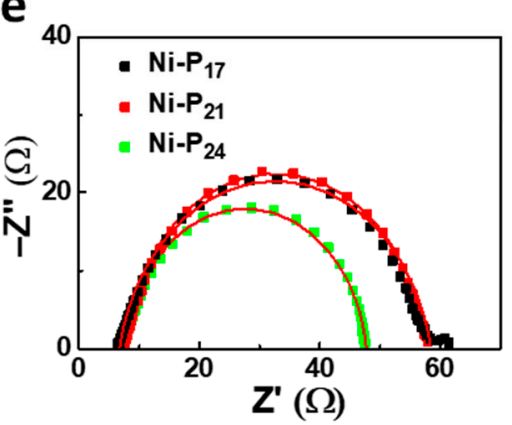

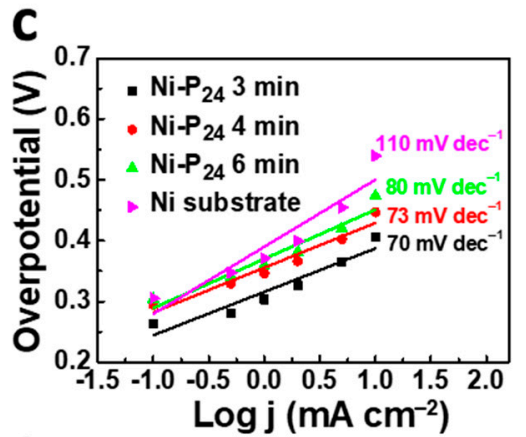

f

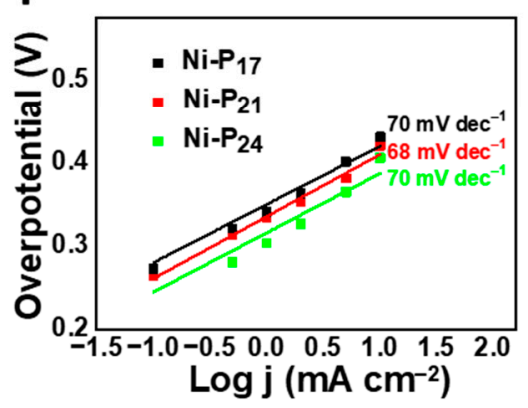

Figure 3. (a) Polarization curves, (b) Nyquist plots with the fitting curves plotted and (c) Tafel plots of Ni- $\mathrm{P}_{24}$ coatings deposited at different growth times and the Ni substrate; (d) polarization curves, (e) Nyquist plots and (f) Tafel plots of the $\mathrm{Ni}-\mathrm{P}$ coatings with different percentages of phosphorus deposited for $3 \mathrm{~min}$.

To ascertain the influence of the phosphorous concentration on the electrochemical activity, we carried out further OER experiments on the thinnest Ni-P samples with different phosphorous concentrations.

The analysis of the polarization and EIS curves reported in Figure 3d,e revealed that, among these samples, the $\mathrm{Ni}-\mathrm{P}_{24}$ catalysts delivered a superior catalytic activity for the OER with the lowest required overpotential and $R_{\mathrm{ct}}$. In regard to the Tafel slopes values, these were quite comparable among the various samples (see Figure $3 \mathrm{f}$ ).

The intrinsic catalytic activity of an electrocatalyst can be better evaluated considering the TOF normalized to each active site. There are two approaches to determine the TOF 
which differ in the method of measuring the catalyst number of active sites, that is, the TOF total metal $\left(\mathrm{TOF}_{\mathrm{tm}}\right)$, which establishes the lower limit of the TOF, by assuming that all the catalyst atoms participate in OER electrocatalysis [44], and the TOF redox, which involves taking into account only the number of metal cations that are electrochemically active, by integrating the redox waves of catalysts displaying clear redox features in the polarization curves (details included in the ESI) [30,45]. As advocated by other authors [44], adopting the former method for TOF estimation is incorrect and misleading, since the TOFsdetermined assuming that the entire mass of the loaded catalyst is active may differ by several orders of magnitude. It is worth noting that most studies do not include TOF determination in electrochemical investigations. Nevertheless, the turnover frequencies are a useful metric to gain a better understanding of the intrinsic catalytic activity, since they are independent of catalyst loading. Herein, we report the $\mathrm{TOF}_{\mathrm{tm}}$ and $\mathrm{TOF}_{\text {redox }}$ values obtained in the 300-400 $\mathrm{mV}$ overpotential range, in which the OER is in full operation.

Figure 4 summarizes the trends of the $\mathrm{TOF}_{\mathrm{tm}}$ and $\mathrm{TOF}_{\text {redox }}$ values for the Ni-P alloys grown at different deposition times and with different phosphorus concentrations. Clearly, in all cases, the TOF increases with the applied overpotential for kinetics reasons. Remarkably, the spread between the $\mathrm{TOF}_{\mathrm{tm}}$ and $\mathrm{TOF}_{\text {redox }}$ values becomes more pronounced by increasing the deposition time; this again emphasizes that the more reliable $\mathrm{TOF}_{\text {redox }}$ method, where the surface active metal sites are calculated from the redox active peak current, should be used.
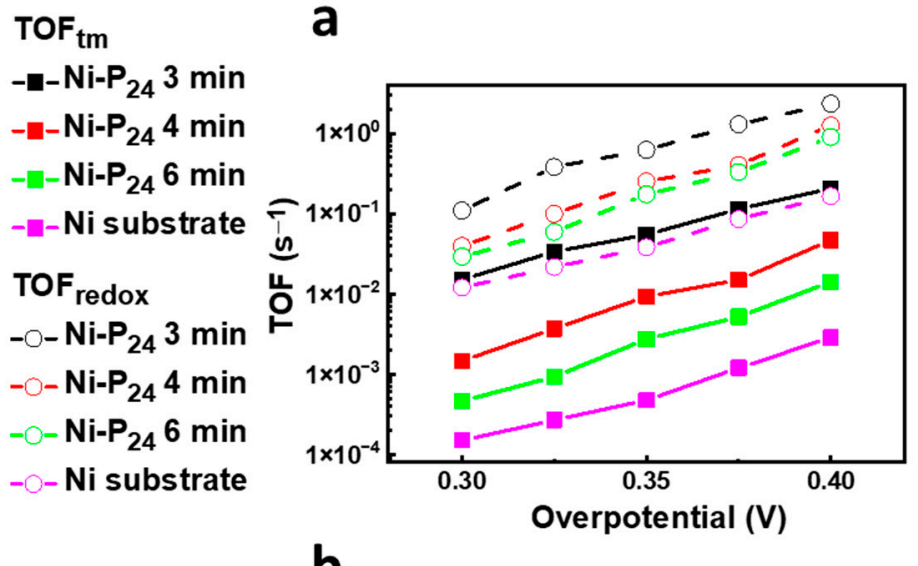

\section{b}

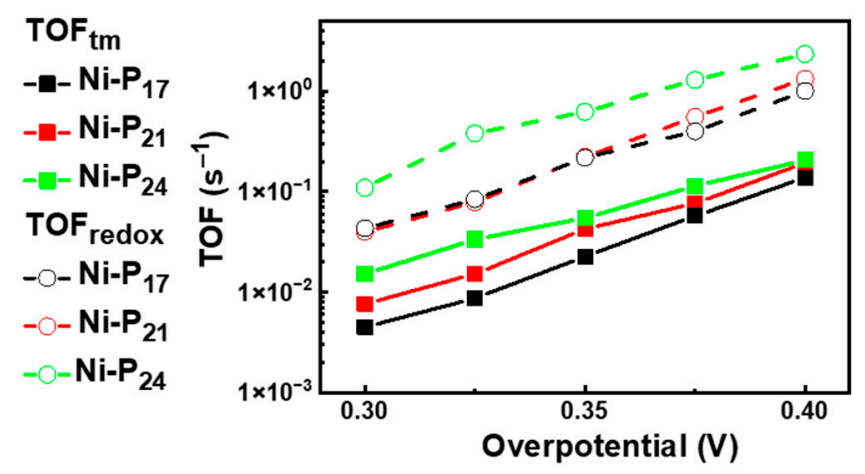

Figure 4. $\mathrm{TOF}_{\mathrm{tm}}$ and $\mathrm{TOF}_{\text {redox }}$ of (a) $\mathrm{Ni}-\mathrm{P}_{24}$ samples deposited at different growth times, and (b) $\mathrm{Ni}-\mathrm{P}$ coatings with different percentages of phosphorus deposited for $3 \mathrm{~min}$.

Significantly, the TOF values obtained for the Ni- $\mathrm{P}_{24}$ catalyst deposited for 3 min generally outperformed those of $\mathrm{Ni}-\mathrm{P}_{24}$ catalysts deposited for longer amounts of time at each specific overpotential (Figure 4a), revealing that the thinnest catalyst displayed the fastest rate of $\mathrm{O}_{2}$ production, thus demonstrating the highest Faradaic efficiency among all samples. Similar results were found for $\mathrm{Ni}-\mathrm{P}_{17}$ and $\mathrm{Ni}-\mathrm{P}_{21}$ catalysts (Figure $\mathrm{S} 4 \mathrm{a}, \mathrm{b}$ ). The TOF 
values determined for the $\mathrm{Ni}-\mathrm{P}_{17}, \mathrm{Ni}-\mathrm{P}_{21}$ and $\mathrm{Ni}-\mathrm{P}_{24}$ samples, reported in Figure $4 \mathrm{~b}$, point to a higher intrinsic catalytic activity of the $\mathrm{Ni}-\mathrm{P}_{24}$ catalysts. Notably, the $\mathrm{Ni}-\mathrm{P}_{24}$ catalysts show $\mathrm{TOF}_{\mathrm{tm}}$ values that are quite comparable with those presented in the literature, while the $\mathrm{TOF}_{\text {redox }}$ values overmatch those of other reported Ni-P-based electrocatalysts (see Table 2).

The remarkable TOF values found for this electrode are even more meaningful, indicating an efficient utilization of the electroactive sites for oxygen production.

The superior activity of the sample with a major phosphorous concentration deserves a comment. Compared to unalloyed $\mathrm{Ni}$ and $\mathrm{P}$ metals, in Ni-P catalysts, the $\mathrm{Ni}$ atoms are more positively charged $\left(\mathrm{Ni}^{\delta+}\right)$, while the $\mathrm{P}$ atoms are more negatively charged $\left(\mathrm{P}^{\delta-}\right)$. The partially charged nature of both elements in nickel phosphide allows a more efficient charge transfer between $\mathrm{Ni}$ and $\mathrm{P}$, which is further enhanced as the value of $\delta$ becomes higher [46]. Furthermore, as reported by J. Li et al. [47], the lower the Ni/P atomic ratio, the higher the average valence state $\left(\delta^{+}\right)$of the Ni metal active sites in Ni-P catalysts; this can explain the superior intrinsic catalytic activity of $\mathrm{Ni}-\mathrm{P}_{24}$ among the present $\mathrm{Ni}-\mathrm{P}$ catalysts.

Table 2. Activity metrics of Ni-P-based electrocatalysts for the OER.

\begin{tabular}{|c|c|c|c|c|c|c|c|}
\hline Catalyst Material & Electrolyte & $\begin{array}{l}\text { Overpotential } \\
\text { at } 10 \mathrm{~mA} \\
\mathrm{~cm}^{-2}(\mathrm{mV})\end{array}$ & 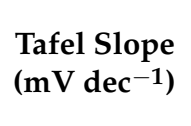 & $\begin{array}{l}\mathrm{TOF}_{\mathrm{tm}} \\
\left(\mathrm{s}^{-1}\right)\end{array}$ & $\begin{array}{c}\text { TOF }_{\text {redox }} \\
\left(\mathrm{s}^{-1}\right)\end{array}$ & Electrode & Reference \\
\hline $\mathrm{NiP}$ nanoparticles & $1 \mathrm{M} \mathrm{KOH}$ & 380 & 106 & & & GCE & [48] \\
\hline NiP nanosheets & $1 \mathrm{M} \mathrm{KOH}$ & 230 & 68 & & $\begin{array}{c}0.0058 \\
(350 \mathrm{mV})\end{array}$ & Carbon fiber & [49] \\
\hline $\begin{array}{c}\mathrm{Ni}_{2} \mathrm{P} \\
\text { superstructures }\end{array}$ & $1 \mathrm{M} \mathrm{KOH}$ & 200 & 72 & & $\begin{array}{c}0.015 \\
(350 \mathrm{mV})\end{array}$ & Ni foam & [50] \\
\hline $\begin{array}{l}\mathrm{Ni}_{2} \mathrm{P} \text { microarrays } \\
\mathrm{Ni}_{2} \mathrm{P} \text { nanowires }\end{array}$ & $\begin{array}{l}1 \mathrm{M} \mathrm{KOH} \\
1 \mathrm{M} \mathrm{KOH}\end{array}$ & $\begin{array}{l}305 \\
400\end{array}$ & $\begin{array}{c}110 \\
60\end{array}$ & & & $\begin{array}{l}\text { Ni foam } \\
\text { FTO }\end{array}$ & $\begin{array}{l}{[51]} \\
{[52]}\end{array}$ \\
\hline NiP nanocrystals & $1 \mathrm{M} \mathrm{KOH}$ & 260 & 62 & $\begin{array}{c}0.074 \\
(300 \mathrm{mV})\end{array}$ & & GCE & [53] \\
\hline $\begin{array}{l}\text { NiP nanocatalysts } \\
\text { NiP films }\end{array}$ & $\begin{array}{l}1 \mathrm{M} \mathrm{KOH} \\
1 \mathrm{M} \mathrm{KOH}\end{array}$ & $\begin{array}{l}330 \\
344\end{array}$ & $\begin{array}{l}92 \\
49\end{array}$ & & & $\begin{array}{c}\text { GCE } \\
\text { Copper foil }\end{array}$ & $\begin{array}{l}{[54]} \\
{[55]}\end{array}$ \\
\hline $\mathrm{Ni}_{2} \mathrm{P}$ nanoparticles & $1 \mathrm{M} \mathrm{KOH}$ & 310 & 71 & $\begin{array}{c}0.05 \\
(400 \mathrm{mV})\end{array}$ & & $\begin{array}{l}\text { Carbon } \\
\text { paper }\end{array}$ & [22] \\
\hline $\mathrm{Ni}_{2} \mathrm{P}$ nanoparticles & $1 \mathrm{M} \mathrm{KOH}$ & 350 & 72 & & & GCE & [56] \\
\hline NiP spheres & $1 \mathrm{M} \mathrm{KOH}$ & 307 & 107 & & $\begin{array}{c}0.16 \\
(350 \mathrm{mV})\end{array}$ & $\begin{array}{l}\text { Carbon } \\
\text { paper }\end{array}$ & [57] \\
\hline $\mathrm{Ni}_{2} \mathrm{P}$ nanowires & $1 \mathrm{M} \mathrm{KOH}$ & 290 & 47 & $\begin{array}{c}0.012 \\
(300 \mathrm{mV})\end{array}$ & & GCE & [58] \\
\hline $\mathrm{Ni}_{2} \mathrm{P}$ nanosheets & $1 \mathrm{M} \mathrm{KOH}$ & N.A. & 78 & 0.01 & 0.11 & Ni foam & [59] \\
\hline NiP nanocoatings & $1 \mathrm{M} \mathrm{КОН}$ & 388 & 70 & $\begin{array}{c}(300 \mathrm{mV}) \\
0.05 \\
(350 \mathrm{mV})\end{array}$ & $\begin{array}{c}(300 \mathrm{mV}) \\
0.62 \\
(350 \mathrm{mV})\end{array}$ & Ni flat & This work \\
\hline NiP nanocoatings & $1 \mathrm{M} \mathrm{KOH}$ & 335 & 71 & & & Ni foam & This work \\
\hline
\end{tabular}

Summarizing all the electrochemical results hitherto reported, our $\mathrm{Ni}-\mathrm{P}_{24}$ sample deposited for $3 \mathrm{~min}$ ensures the highest intrinsic electrocatalytic OER performance. Indeed, this electrocatalyst showed the best catalytic activity due to its low values of overpotential, charge transfer resistance and Tafel slope and its high TOF.

An effective approach to optimize the performance of electrocatalysts for water splitting is to deposit them on an electrode with a highly porous structure. In this regard, the use of $\mathrm{Ni}$ foam as the electrode endows electrocatalysts with a larger specific surface area and more active sites [17]. Prompted by the interesting results observed in the Ni-P samples deposited on the nickel flat electrode, we decided to deepen our investigation on the nickel foam electrode, in order to evidence how the appropriate nanoporous structure of the electrode may affect the electrochemical performance. The depositions on nickel 
foam were carried out adopting the same experimental conditions as those used for the $\mathrm{Ni}-\mathrm{P}_{24}$ coating, which was demonstrated to be the most performant Ni-P alloy. As can be seen in Figure 5a, the polarization curves indicate that the deposition of $\mathrm{Ni}-\mathrm{P}_{24}$ onto nickel foam enhanced its electrocatalytic performance, since a lower overpotential of $335 \mathrm{mV}$ at a current density of $10 \mathrm{~mA} \mathrm{~cm}{ }^{-2}$ was attained. Remarkably, this value is comparable or even superior to that of other Ni-P electrocatalysts in alkaline media (see Table 2). Concerning the samples deposited for longer times, the results confirm the trend of an overpotential increase with the deposition time. Meanwhile, the OER activity of the bare Ni foam is faint, confirming the pivotal role of the Ni-P coating in the electrochemical performance enhancement. The superior charge transfer capability of the nickel foam electrode compared to the $\mathrm{Ni}$ flat electrode was confirmed by EIS measurements (Figure $5 b$ ), showing an $R_{c t}$ value that reaches a very low value of only $4 \mathrm{ohms}$ for the thinnest sample. An overview of the overpotential and $R_{c t}$ values found for the four samples is presented in Figure $5 \mathrm{c}$.

a
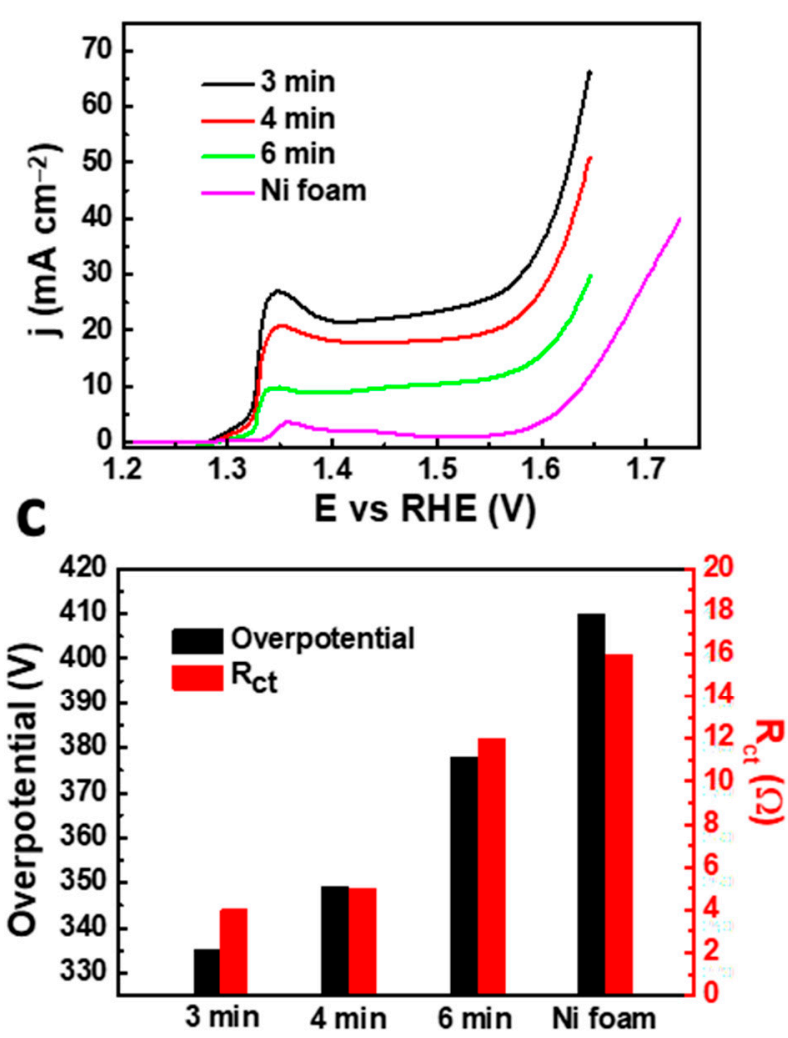

b
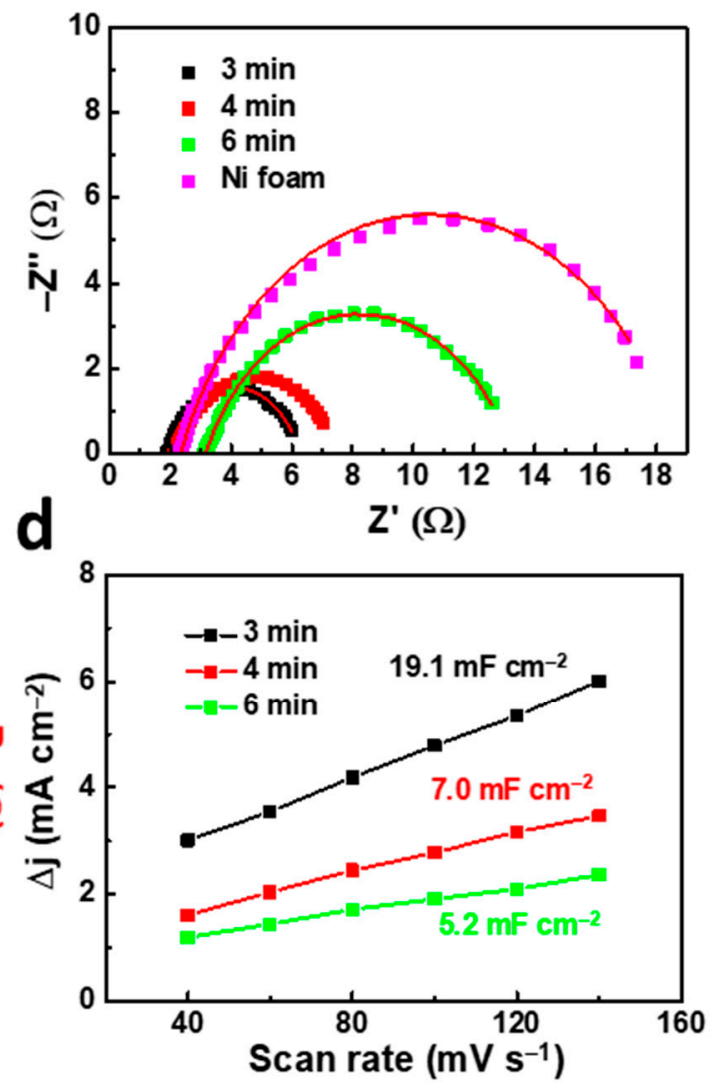

Figure 5. (a) Polarization curves of $\mathrm{Ni}$ foam and Ni- $\mathrm{P}_{24}$ coatings deposited on $\mathrm{Ni}$ foam at different times; (b) Nyquist plots of the four samples with the fitting curves plotted; (c) comparison of overpotential and charge transfer resistance among the four samples; $(\mathbf{d})$ the difference between the anodic and cathodic current densities $\left(\Delta \mathrm{J}=-\mathrm{J}_{\mathrm{a}}-\mathrm{J}_{\mathrm{c}}\right)$ plotted against the scan rate for catalysts deposited at different times.

Both the lower overpotential and $R_{c t}$ values measured for the samples grown on nickel foam clearly suggest that the Ni-P catalyst deposited on this highly porous electrode can expose and utilize more electroactive sites to boost the electrocatalytic activity.

To thoroughly understand the reasons for the improvement in OER performances upon reducing the catalyst size, we calculated the electrochemical surface area (ECSA) of the catalysts, which is correlated with the surface capacitance. The electrochemical double layer capacitance $\left(\mathrm{C}_{\mathrm{dl}}\right)$ was determined by plotting the capacitive current density, 
calculated from the cyclic voltammogram (CV) curves (Figure S5 and details included in ESI), against the scan rate (Figure $5 \mathrm{~d}$ ).

The $\mathrm{C}_{\mathrm{dl}}$ of Ni-P deposited for $3 \mathrm{~min}\left(14.5 \mathrm{mF} \mathrm{cm}^{-2}\right)$ was higher than that of samples deposited for $4\left(8.0 \mathrm{mF} \mathrm{cm}^{-2}\right)$ and $6 \mathrm{~min}\left(5.5 \mathrm{mF} \mathrm{cm}^{-2}\right)$. According to the formula ECSA $=C_{\mathrm{dl}} / \mathrm{C}_{\mathrm{S}}$, the calculated ECSA was $362.5,200.0$ and $137.5 \mathrm{~cm}^{2}$ for the Ni-P catalysts deposited for 3, 4 and $6 \mathrm{~min}$, respectively, revealing that the enhanced electrocatalytic OER activity of the thinnest catalysts is associated with the higher ECSA, which bestows more effective active sites on their surface.

Finally, the durability of the Ni-P/nickel foam electrode was tested using chronopotentiometry. As displayed in Figure S6, the voltage at a current density of $10 \mathrm{~mA} \mathrm{~cm}^{-2}$ was nearly constant upon $12 \mathrm{~h}$ of testing, demonstrating the very good stability of the electrode.

\section{Conclusions}

In summary, we used a feasible electroless plating method to develop high-efficiency $\mathrm{Ni}-\mathrm{P}$ OER catalysts. The comprehensive study, which included properly tuning the plating parameters, allowed for size and compositional control of the deposited alloys. By reducing the thickness, the activity of the catalysts was greatly improved. Moreover, tuning the hypophosphite concentration in the plating bath enabled control of the Ni-P composition in the alloys. The electrochemical measurements showed that the higher the phosphorus content in the alloy, the higher the OER catalytic activity. The Ni-P alloys with optimized size and composition grown on nickel foam substrates required only $335 \mathrm{mV}$ to deliver a current density of $10 \mathrm{~mA} \mathrm{~cm}^{-2}$ for the OER under alkaline conditions, where the charge transfer resistance was as low as $4 \mathrm{ohms}$, and the TOF had a high value of $0.62 \mathrm{~s}^{-1}$. As key factors, the high activity, good stability and low price of the present Ni-P alloys realized by a facile electroless deposition method open the route towards large-scale and long-term applications of metal phosphide OER catalysts, rendering them compelling candidates for application in commercial electrolyzers.

Supplementary Materials: The following are available online at https://www.mdpi.com/article/ 10.3390/nano11113010/s1, Figure S1: SEM micrograph after the OER of Ni-P 24 coating deposited for 6 minutes, Figure S2: (a) Polarization curves, (b) Nyquist plots with the fitting curves plotted and (c) Tafel plots of $\mathrm{Ni}-\mathrm{P}_{17}$ coatings deposited at different times, Figure S3: (a) Polarization curves, (b) Nyquist plots with the fitting curves plotted and (c) Tafel plots of Ni-P $\mathrm{P}_{21}$ coatings deposited at

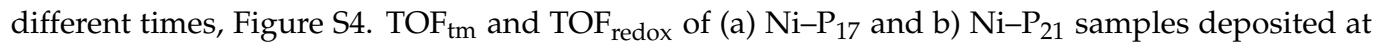
different growth times, Figure S5: Cyclic voltammograms in the region of $0.15-0.25 \mathrm{~V}$ vs. $\mathrm{Hg} / \mathrm{Hg}_{2} \mathrm{Cl}_{2}$ with different potential scanning rates of $\mathrm{Ni}-\mathrm{P}_{24}$ coatings deposited on $\mathrm{Ni}$ foam for (a) 3, (b) 4 and (c) 6 minutes, Figure S6: Chronopotentiometric response of $\mathrm{Ni}-\mathrm{P}_{24}$ sample deposited for 3 min on nickel foam held at $10 \mathrm{~mA} \mathrm{~cm}^{-2}$ for $12 \mathrm{~h}$.

Author Contributions: Conceptualization, S.B., M.U. and S.M.; methodology, S.B. and M.U.; validation, S.M.; formal analysis, S.B. and S.M.; investigation, S.B., S.C. and A.L.P.; resources, A.T.; data curation, S.B.; writing — original draft preparation, S.B.; writing—review and editing, S.B. and S.M.; visualization, S.B.; supervision, S.M.; project administration, S.C. and A.T.; funding acquisition, A.T. All authors have read and agreed to the published version of the manuscript.

Funding: This research was funded by the project AIM1804097-Programma Operativo Nazionale FSE -FESR "Ricerca e Innovazione 2014-2020" and was supported by the project "Programma di ricerca di ateneo UNICT 2020-22" linea 2. This work was partially supported by Bio-Nanotech Research and Innovation Tower grant BRIT PONa3_00136, University of Catania, for the substrate deposition with the electron beam evaporator KE500 from Kenosistec.

Institutional Review Board Statement: Not applicable.

Informed Consent Statement: Not applicable.

Data Availability Statement: The data presented in this study are available in supplementary material. 
Acknowledgments: The authors would like to acknowledge Maria Josè Lo Faro and Paolo Musumeci for their support in the substrate preparation. Authors are grateful to Giuseppe Pantè (CNR-IMM) for his technical support.

Conflicts of Interest: The authors declare no conflict of interest.

\section{References}

1. Wu, D.; Kusada, K.; Yoshioka, S.; Yamamoto, T.; Toriyama, T.; Matsumura, S.; Chen, Y.; Seo, O.; Kim, J.; Song, C.; et al. Efficient overall water splitting in acid with anisotropic metal nanosheets. Nat. Commun. 2021, 12, 1145. [CrossRef]

2. Landsmann, S.; Surace, Y.; Trottmann, M.; Dilger, S.; Weidenkaff, A.; Pokrant, S. Controlled design of functional nano-coatings: Reduction of loss mechanisms in photoelectrochemical water splitting. ACS Appl. Mater. Interfaces 2016, 8, 12149-12157. [CrossRef] [PubMed]

3. Sun, H.; Xu, X.; Song, Y.; Zhou, W.; Shao, Z. Designing high-valence metal sites for electrochemical water splitting. Adv. Funct. Mater. 2021, 31, 2009779. [CrossRef]

4. Zhou, Y.; Li, J.; Gao, X.; Chu, W.; Gao, G.; Wang, L.-W. Recent advances in single-atom electrocatalysts supported on twodimensional materials for the oxygen evolution reaction. J. Mater. Chem. A 2021, 9, 9979-9999. [CrossRef]

5. Liu, Y.; Li, Y.; Wu, Q.; Su, Z.; Wang, B.; Chen, Y.; Wang, S. Hollow CoP/FeP 4 Heterostructural nanorods interwoven by CNT as a highly efficient electrocatalyst for oxygen evolution reactions. Nanomaterials 2021, 11, 1450. [CrossRef] [PubMed]

6. Reier, T.; Oezaslan, M.; Strasser, P. Electrocatalytic oxygen evolution reaction (OER) on Ru, Ir, and Pt catalysts: A comparative study of nanoparticles and bulk materials. ACS Catal. 2012, 2, 1765-1772. [CrossRef]

7. Jamesh, M.-I.; Sun, X. Recent progress on earth abundant electrocatalysts for oxygen evolution reaction (OER) in alkaline medium to achieve efficient water splitting-A review. J. Power Sources 2018, 400, 31-68. [CrossRef]

8. Rongé, J.; Dobbelaere, T.; Henderick, L.; Minjauw, M.M.; Sree, S.P.; Dendooven, J.; Martens, J.A.; Detavernier, C. Bifunctional earth-abundant phosphate/phosphide catalysts prepared via atomic layer deposition for electrocatalytic water splitting. Nanoscale Adv. 2019, 1, 4166-4172. [CrossRef]

9. Deng, B.; Liang, J.; Yue, L.; Li, T.; Liu, Q.; Liu, Y.; Gao, S.; Alshehri, A.A.; Alzahranie, K.A.; Luo, Y.; et al. CoFe-LDH nanowire arrays on graphite felt: A high-performance oxygen evolution electrocatalyst in alkaline media. Chin. Chem. Lett. 2021. [CrossRef]

10. McCrory, C.C.K.; Jung, S.; Peters, J.C.; Jaramillo, T.F. Benchmarking heterogeneous electrocatalysts for the oxygen evolution reaction. J. Am. Chem. Soc. 2013, 135, 16977-16987. [CrossRef] [PubMed]

11. Shit, S.; Bolar, S.; Murmu, N.C.; Kuila, T. An account of the strategies to enhance the water splitting efficiency of noble-metal-free electrocatalysts. J. Energy Chem. 2021, 59, 160-190. [CrossRef]

12. McCrory, C.C.L.; Jung, S.; Ferrer, I.M.; Chatman, S.M.; Peters, J.C.; Jaramillo, T.F. Benchmarking hydrogen evolving reaction and oxygen evolving reaction electrocatalysts for solar water splitting devices. J. Am. Chem. Soc. 2015, 137, 4347-4357. [CrossRef] [PubMed]

13. Wang, J.-W.; Liu, W.-J.; Zhong, D.-C.; Lu, T.-B. Nickel complexes as molecular catalysts for water splitting and $\mathrm{CO}_{2}$ reduction Coord. Chem. Rev. 2019, 378, 237-261. [CrossRef]

14. Ye, C.; Zhang, L.; Yue, L.; Deng, B.; Cao, Y.; Liu, Q.; Luo, Y.; Lu, S.; Zheng, B.; Sun, X. A NiCo LDH nanosheet array on graphite felt: An efficient 3D electrocatalyst for the oxygen evolution reaction in alkaline media. Inorg. Chem. Front. 2021, 8, 3162-3166. [CrossRef]

15. Ding, P.; Meng, C.; Liang, J.; Li, T.; Wang, Y.; Liu, Q.; Luo, Y.; Cui, G.; Asiri, A.M.; Lu, S.; et al. NiFe Layered-Double-Hydroxide Nanosheet Arrays on Graphite Felt: A 3D Electrocatalyst for Highly Efficient Water Oxidation in Alkaline Media. Inorg. Chem. 2021, 60, 12703-12708. [CrossRef] [PubMed]

16. Sekar, S.; Kim, D.Y.; Lee, S. Excellent oxygen evolution reaction of activated carbon-anchored NiO nanotablets prepared by green routes. Nanomaterials 2020, 10, 1382. [CrossRef]

17. Wang, K.; Sun, K.; Yu, T.; Liu, X.; Wang, G.; Jiang, L.; Xie, G. Facile synthesis of nanoporous Ni-Fe-P bifunctional catalysts with high performance for overall water splitting. J. Mater. Chem. A 2019, 7, 2518-2523. [CrossRef]

18. Guo, X.; Qian, Y.; Zhang, W.; Qian, C.; Xu, F.; Qian, S.; Yang, H.; Yuan, A.; Fan, T. Amorphous Ni-P with hollow dendritic architecture as bifunctional electrocatalyst for overall water splitting. J. Alloys Compd. 2018, 765, 835-840. [CrossRef]

19. Chang, B.; Hao, S.; Ye, Z.; Yang, Y. A self-supported amorphous Ni-P alloy on a CuO nanowire array: An efficient 3D electrode catalyst for water splitting in alkaline media. Chem. Commun. 2018, 54, 2393-2396. [CrossRef]

20. Yu, F.; Zhou, H.; Huang, Y.; Sun, J.; Qin, F.; Bao, J.; Goddard, W.A., III; Chen, S.; Ren, Z. High-performance bifunctional porous non-noble metal phosphide catalyst for overall water splitting. Nat. Commun. 2018, 9, 2551. [CrossRef]

21. Read, C.G.; Callejas, J.F.; Holder, C.F.; Schaak, R.E. General strategy for the synthesis of transition metal phosphide films for electrocatalytic hydrogen and oxygen evolution. ACS Appl. Mater. Interfaces 2016, 8, 12798-12803. [CrossRef]

22. Xu, J.; Wei, X.-K.; Costa, J.D.; Lado, J.L.; Owens-Baird, B.; Gonçalves, L.P.L.; Fernandes, S.P.S.; Heggen, M.; Petrovykh, D.Y.; Dunin-Borkowski, R.E.; et al. Interface engineering in nanostructured nickel phosphide catalyst for efficient and stable water oxidation. ACS Catal. 2017, 7, 5450-5455. [CrossRef]

23. Kumar, P.; Murthy, A.P.; Bezerra, L.S.; Martini, B.K.; Maia, G.; Madhavana, J. Carbon supported nickel phosphide as efficient electrocatalyst for hydrogen and oxygen evolution reactions. Int. J. Hydrogen Energy 2021, 46, 622-632. [CrossRef] 
24. Li, Z.B.; Wang, J.; Liu, X.J.; Li, R.; Wang, H.; Wu, Y.; Wang, X.Z.; Lu, Z.P. Self-supported NiCoP/nanoporous copper as highly active electrodes for hydrogen evolution reaction. Scr. Mater. 2019, 173, 51-55. [CrossRef]

25. Song, D.; Hong, D.; Kwon, Y.; Kim, H.; Shin, J.; Lee, H.M.; Cho, E. Highly porous Ni-P electrode synthesized by an ultrafast electrodeposition process for efficient overall water electrolysis. J. Mater. Chem. A 2020, 8, 12069-12079. [CrossRef]

26. Sumi, V.S.; Sha, M.A.; Arunima, S.R.; Shibli, S.M.A. Development of a novel method of NiCoP alloy coating for electrocatalytic hydrogen evolution reaction in alkaline media. Electrochim. Acta 2019, 303, 67-77. [CrossRef]

27. SIMNRA. Available online: https://www2.ipp.mpg.de/ \{\}mam/ (accessed on 5 October 2021).

28. Parkinson, R. Properties and applications of electroless nickel. Nickel Dev. Inst. Tech. Ser. 1997, 37, 1-37.

29. Geerts, L.; Cosentino, S.; Liao, T.-W.; Yadav, A.; Lin, P.-C.; Zharinov, V.S.; Hu, K.-J.; Longo, A.; Pereira, L.M.C.; Grandjean, D.; et al. Highly active oxygen evolution reaction model electrode based on supported gas-phase NiFe clusters. Catal. Today 2019, 334, 59-67. [CrossRef]

30. Stevens, M.B.; Enman, L.J.; Batchellor, A.S.; Cosby, M.R.; Vise, A.E.; Trang, C.D.M.; Boettcher, S.W. Measurement techniques for the study of thin film heterogeneous water oxidation electrocatalysts. Chem. Mater. 2017, 29, 120-140. [CrossRef]

31. Zhang, B.; Lui, Y.H.; Zhou, L.; Tang, X.; Hu, S. An alkaline electro-activated Fe-Ni phosphide nanoparticle-stack array for high-performance oxygen evolution under alkaline and neutral conditions. J. Mater. Chem. A 2017, 5, 13329-13335. [CrossRef]

32. Cosentino, S.; Urso, M.; Torrisi, G.; Battiato, S.; Priolo, F.; Terrasi, A.; Mirabella, S. High intrinsic activity of the oxygen evolution reaction in low-cost $\mathrm{NiO}$ nanowall electrocatalysts. Mater. Adv. 2020,1, 1971-1979. [CrossRef]

33. Yang, Q.; Huang, C.L.Z.; Zhang, C. Amorphous film of ternary NiCoP alloy on Ni foam for efficient hydrogen evolution by electroless deposition. Int. J. Hydrogen Energy 2018, 43, 7872-7880. [CrossRef]

34. Lucas, I.; Perez, L.; Aroca, C.; Sánchez, P.; López, E.; Sánchez, M.C. Magnetic properties of CoP alloys electrodeposited at room temperature. J. Magn. Magn. Mater. 2005, 290-291, 1513-1516. [CrossRef]

35. Sultana, U.K.; O'Mullane, A.P. Electrochemically fabricated Ni-P, Ni-S and Ni-Se materials for overall water splitting: Investigating the concept of bifunctional electrocatalysis. ChemElectroChem 2019, 6, 2630-2637. [CrossRef]

36. Xu, C.; Chen, L.; Yu, L.; Zhang, J.; Zhang, Z.; Wang, J. Effect of pickling processes on the microstructure and properties of electroless Ni-P coating on Mg-7.5Li-2Zn-1Y alloy. Prog. Nat. Sci. Mater. Int. 2014, 24, 655-662. [CrossRef]

37. Xie, R.; Zhang, H.; Zou, J.; Lin, N.; Ma, Y.; Wan, Z.; Tian, W.; Yao, X.; Han, P.; Wang, Z.; et al. Effect of adding Lanthanum (La ${ }^{3+}$ ) on surface performance of Ni-P electroless plating coatings on RB400 support anchor rod steel. Int. J. Electrochem. Sci. 2016, 11, 3269-3284. [CrossRef]

38. Moreau, L.M.; Ha, D.-H.; Zhang, H.; Hoyden, R.; Muller, D.A.; Robinson, R.D. Defining Crystalline/Amorphous Phases of Nanoparticles through X-ray Absorption Spectroscopy and X-ray Diffraction: The Case of Nickel Phosphide. Chem. Mater. 2013, 25, 2394-2403. [CrossRef]

39. Xu, X.; Cui, Z.D.; Zhu, S.L.; Liang, Y.Q.; Yang, X.J. Preparation of nickel-coated graphite by electroless plating under mechanical or ultrasonic agitation. Surf. Coat. Technol. 2014, 240, 425-431. [CrossRef]

40. Szász, A.; Kojnok, J.; Kertész, L.; Hegedüs, Z. On the formation of electroless amorphous layers: I. Phenomenological description of NiP deposited on $\mathrm{Cu}$ and Fe substrates. J. Non-Cryst. Solids 1983, 57, 213-224. [CrossRef]

41. Hoang, V.C.; Dinh, K.N.; Gomes, V.G. Hybrid Ni/NiO composite with N-doped activated carbon from waste cauliflower leaves: A sustainable bifunctional electrocatalyst for efficient water splitting. Carbon 2020, 157, 515-524. [CrossRef]

42. Iwu, K.O.; Lombardo, A.; Sanz, R.; Scirè, S.; Mirabella, S. Facile synthesis of Ni nanofoam for flexible and low-cost non-enzymatic glucose sensing. Sens. Actuators B Chem. 2016, 224, 764-771. [CrossRef]

43. Anantharaj, S.; Noda, S. Appropriate use of electrochemical impedance spectroscopy in water splitting electrocatalysis. ChemElectroChem 2020, 7, 2297-2308. [CrossRef]

44. Kibsgaard, J.; Chorkendorff, I. Considerations for the scaling-up of water splitting catalysts. Nat. Energy 2019, 4, 430-433. [CrossRef]

45. Anantharaj, S.; Ede, S.R.; Karthick, K.; Sankar, S.S.; Sangeetha, K.; Karthik, P.E.; Kundu, S. Precision and correctness in the evaluation of electrocatalytic water splitting: Revisiting activity parameters with a critical assessment. Energy Environ. Sci. 2018, 11, 744-771. [CrossRef]

46. Burns, A.W.; Layman, K.A.; Bale, D.H.; Bussell, M.E. Understanding the relationship between composition and hydrodesulfurization properties for cobalt phosphide catalysts. Appl. Catal. A Gen. 2008, 343, 68-76. [CrossRef]

47. Li, J.; Li, J.; Zhou, X.; Xia, Z.; Gao, W.; Ma, Y.; Qu, Y. Highly efficient and robust nickel phosphides as bifunctional electrocatalysts for overall water-splitting. ACS Appl. Mater. Interfaces 2016, 8, 10826-10834. [CrossRef]

48. Shanmugam, S.; Sivanantham, A.; Matsunaga, M.; Simon, U.; Osaka, T. Metal phosphide nanoparticles embedded in carbon as efficient electrocatalyst for oxygen evolution reaction. Electrochim. Acta 2019, 297, 749-754. [CrossRef]

49. Shifa, T.A.; Yusupov, K.; Solomon, G.; Gradone, A.; Mazzaro, R.; Cattaruzza, E.; Vomiero, A. In situ-generated oxide in Sn-doped nickel phosphide enables ultrafast oxygen evolution. ACS Catal. 2021, 11, 4520-4529. [CrossRef]

50. You, B.; Jiang, N.; Sheng, M.; Bhushan, M.W.; Sun, Y. Hierarchically porous urchin-like $\mathrm{Ni}_{2} \mathrm{P}$ superstructures supported on nickel foam as efficient bifunctional electrocatalysts for overall water splitting. ACS Catal. 2016, 6, 714-721. [CrossRef]

51. Liu, X.X.; He, Q.; Xiao, S.; Li, X.; Chang, L.; Xiang, Y.; Hu, K.; Niu, X.; Wu, R.; Chen, J.S. Realizing efficient overall water splitting by tuning the cobalt content in self-supported $\mathrm{Ni}_{\mathrm{x}}-\mathrm{Co}_{\mathrm{y}}-\mathrm{P}$ microarrays. ChemElectroChem 2021, 8, 1307-1315. [CrossRef] 
52. Han, A.; Chen, H.; Sun, Z.; Xu, J.; Du, P. High catalytic activity for water oxidation based on nanostructured nickel phosphide precursors. Chem. Commun. 2015, 51, 11626. [CrossRef] [PubMed]

53. Yan, L.; Jiang, H.; Xing, Y.; Wang, Y.; Wang, D.; Liu, D.; Gu, X.; Dai, P.; Li, L.; Zhao, X. Nickel metal-organic framework implanted on graphene and incubated to be ultrasmall nickel phosphide nanocrystals acts as a highly efficient water splitting electrocatalyst. J. Mater. Chem. A 2018, 6, 1682. [CrossRef]

54. Fu, S.; Zhu, C.; Song, J.; Engelhard, M.H.; Li, X.; Du, D.; Lin, Y. Highly ordered mesoporous bimetallic phosphides as efficient oxygen evolution electrocatalysts. ACS Energy Lett. 2016, 1, 792-796. [CrossRef]

55. Jiang, N.; You, B.; Sheng, M.; Sun, Y. Bifunctionality and mechanism of electrodeposited nickel-phosphorous films for efficient overall water splitting. ChemCatChem 2016, 8, 106-112. [CrossRef]

56. Sankar, S.; Sugawara, Y.; Aravindh, S.A.; Jose, R.; Tamaki, T.; Anilkumar, G.M.; Yamaguchi, T. Tuning palladium nickel phosphide toward efficient oxygen evolution performance. ACS Appl. Energy Mater. 2020, 3, 879-888. [CrossRef]

57. Yin, Z.; Zhu, C.; Li, C.; Zhang, S.; Zhang, X.; Chen, Y. Hierarchical nickel-cobalt phosphide yolk-shell spheres as highly active and stable bifunctional electrocatalysts for overall water splitting. Nanoscale 2016, 8, 19129. [CrossRef]

58. Stern, L.-A.; Feng, L.; Song, F.; Hu, X. $\mathrm{Ni}_{2} \mathrm{P}$ as a Janus catalyst for water splitting: The oxygen evolution activity of $\mathrm{Ni}_{2} \mathrm{P}$ nanoparticles. Energy Environ. Sci. 2015, 8, 2347-2351. [CrossRef]

59. Ren, J.; Hu, Z.; Chen, C.; Liu, Y.; Yuan, Z. Integrated $\mathrm{Ni}_{2} \mathrm{P}$ nanosheet arrays on three-dimensional Ni foam for highly efficient water reduction and oxidation. J. Energy Chem. 2017, 26, 1196-1202. [CrossRef] 